\title{
ESTRUTURA ORGANIZACIONAL: Considerações à Modelagem
}

\author{
Organizacional
}

Aristides Alvares DOURADO JUNIOR ${ }^{1}$

Jonilto Costa SOUSA ${ }^{2}$

\author{
${ }^{1}$ Mestrando em Gestão Pública pelo Programa de Pós Graduação em Gestão Pública - PPGP/UnB \\ aristides.jana@gmail.com \\ ${ }^{2}$ Doutor em Administração pela Universidade de Brasília. Professor do Programa de Pós Graduação em Gestão Pública \\ - PPGP/UnB \\ jonilto@unb.br
}

Recebido em: 28/11/2015 - Aprovado em: 18/07/2016 - Disponibilizado em: 18/12/2016

\begin{abstract}
RESUMO
O presente estudo assinala os elementos que corroboram a configuração de estruturas organizacionais públicas ou privadas frente a ambientes de incertezas. Ressalta, a partir de pesquisa bibliográfica sistematizada sobre o tema, a evolução de modelos estruturais (VASCONCELLOS, 1989; DAFT, 2005; OLIVEIRA, 2006; CURY, 2007), destacando formalização, componentes, condicionantes, níveis de influência e abrangência e natureza institucional. Fornece subsídios para análise e contínua reavaliação das estruturas, com o intuito de melhor atender a dinâmica organizacional. O estudo, portanto, revela que as organizações devem se revestir de formalidade estrutural, congregando os sistemas componentes, condicionados e influenciados pelas pessoas, ambiente e natureza da organização em análise.

Palavras-chave: Estrutura Organizacional. Mudança Organizacional. Formalidade. Informalidade. Organizações Públicas.
\end{abstract}

\begin{abstract}
This study points out the elements that support the configuration of public and private organizational structures facing uncertainties environments. Points out, from a systematic literature review on the topic, the evolution of structural models (VASCONCELLOS, 1989; DAFT, 2005; OLIVEIRA, 2006; CURY, 2007), highlighting formalization, components, conditioning, influence levels and scope and institutional. It provides information for analysis and continuous reassessment of structures in order to better meet the organizational dynamics. The study therefore reveals that organizations should have put structural formality, bringing the component systems, conditioned and influenced by people, environment and nature of the organization under review.
\end{abstract}

Keywords: Organizational structure. Organizational change. Formality. Informality. Public organizations.

\section{Introdução}

O estudo trata dos elementos constituintes e condicionantes da configuração das estruturas organizacionais, conforme os fundamentos das ciências da administração. De acordo com Coelho (2004), as organizações existem porque é preciso entender que os usuários/cidadãos carecem de bens e serviços para sobrevivência e de que são elas as responsáveis por essas produções. Então, as instituições públicas e privadas, como quaisquer outras, surgiram para atender às necessidades e desejos da sociedade.

Em estudos organizacionais, Cruz (2007) observa que as instituições, em seu 
processo evolutivo, amoldadas às demandas da sociedade, careceram de estruturação interna na qual ficassem claras as articulações, a divisão de trabalho e atividades e os recursos necessários, em especial os humanos, que pudessem garantir a razão de existência e de sucesso da instituição. Lembra que nem sempre as organizações foram divididas internamente: ao iniciarem suas atividades, a produção era pequena e geralmente voltada para seus idealizadores; não havia a exigência de distribuir tarefas, nem de reunir pessoas em unidades organizacionais de trabalho, conforme ajustamento mútuo de Mintzberg (2006). Contudo, os tempos mudaram, as organizações ganharam complexidade, não podendo mais serem geridas como eram no momento de criação; devem, então, evoluir para novos modelos de gestão flexíveis e dinâmicos que se acomodem ao ambiente de incertezas.

Assim, as organizações, segundo Cury (2007), em busca de maior desempenho e eficácia de seus serviços - consequentemente, de sua própria manutenção de vida evoluíram de uma modelagem patrimonialista (BRESSER-PEREIRA, 1996; FAORO, 2001, Cury, 2007), com forte apego ao patrimônio, para um modelo burocrático, concebido por Weber (2012); posteriormente avançaram para um modelo considerado moderno, flexível, que se adaptava à influência mundial de globalização, desenvolvimento tecnológico e acirrada concorrência - isto, no esforço constante de agradar os usuários/cidadãos (TOFFLER， 1970; BRESSER-PEREIRA, 1996; ABRUCIO, 1997). Essas ingerências também atingiram as organizações públicas, impulsionadas pela demanda por serviços públicos de qualidade e gestão eficiente da coisa pública, fazendo com que também experimentassem esses três modelos de gestão: o patrimonialista, apropriação da coisa pública como um bem particular (BRESSERPEFEIRA, 1996); o burocrático, conforme Weber (2012), caracterizado pelo forte apego às normas; e o gerencialista, mais flexível, herdado da administração privada (MOTTA, 2013).

Nesse contexto, a fim de atender às exigências demandadas da sociedade e cumprir o objetivo de sua criação, torna-se imperativo que as organizações, quer sejam públicas ou privadas, se ajustem quando necessário, dentro desse ambiente organizacional complexo, considerando todas as variáveis que impactem seu funcionamento. Dessa forma, os gerentes organizacionais devem possuir conhecimentos de elementos constituintes e condicionantes de gerência para uma análise administrativa efetiva; considerarão a organização enquanto um sistema de interação vivo, aberto ao ambiente e às pessoas, relacionado-as aos produtos e serviços oferecidos, os quais serão 
devolvidos ao sistema que retroalimentam o processo, como ensina Bertalanffy (1975).

A partir de uma revisão bibliográfica sistematizada, o presente estudo tem como objetivo apontar os elementos a serem considerados na configuração organizacional que viabilize o processo de intervenção organizacional. Para tal intento, buscou-se evidenciar, dentro da literatura existente sobre o tema, os componentes, condicionantes e considerações relevantes que interfiram na formalização de estruturas organizacionais, a fim de que possam dar respostas efetivas num cenário de evolução, demandas e mudanças intempestivas, levando em consideração a abordagem adotada pelo analista organizacional, quando organização pública ou privada (ADIZES, 1996).

\section{Organização: origens e evolução}

A organização, segundo Oliveira (2006), é a função administrativa que se incumbe da ordenação e do agrupamento das atividades e dos recursos necessários, em especial das pessoas, para a consecução da missão institucional. Ademais, Daft (2005, p.222) a define como "a disposição de recursos organizacionais para alcançar as metas estratégicas". Os recursos são refletidos na divisão da mão de obra em departamentos específicos e empregos, nas linhas formais de autoridade e nos mecanismos de coordenação das tarefas organizacionais diversas e alinhamento como arte de definir e aplicar recursos, harmoniosamente, com o fim de atingir os objetivos previamente estabelecidos.

Para que a missão seja atingida, os planos sejam executados e as pessoas possam trabalhar eficientemente, as atividades precisam ser corretamente agrupadas e a autoridade apropriadamente distribuída, capaz de conduzir equipes aos objetivos definidos pela estratégia do negócio. Por esse motivo, ressalta-se que a missão da instituição é sua razão de existir, e os valores devem ser os mais reais e concretos possíveis, de maneira que possam viabilizar a concretização da estratégia.

Cury (2007) lembra que, para atingirem as finalidades, tais instituições devem fazer uso dos principais meios que dispuserem, em especial, dos recursos humanos. Dessa forma, as organizações, pelo agrupamento harmônico dos meios, terão funcionários produzindo mais e melhor e poderão dar respostas cada vez mais adequadas à sociedade. $\mathrm{O}$ autor recorda, ainda, que o estágio atual da organização é resultado do processo de desenvolvimento da sociedade, o qual, saindo do modelo patrimonialista - quando todos os serviços da organização eram simples, com poucas atividades e divisão do trabalho, voltados, geralmente, para seus idealizadores, os 
próprios patrões, e não para a sociedade passa para o modelo de gestão burocrática, baseado na hierarquia, profissionalização, competência definida, amparo nas normas de conduta e formalidade, conforme Weber (2012), até o atual e mais complexo, definido por Toffler (1970), como adhocrático. Ou seja, tornam-se organizações caracterizadas por maior divisão de trabalho, poder, responsabilidade com a informação - divisões planejadas - de modo a continuamente, conforme Mintzberg, Ahlstrand e Lampel (2010), revisar a atuação da organização e a remodelar sua estrutura, quando necessário, a fim de alcançar sua eficiência.
Bertalanffy (1975) entendia as organizações como conjuntos de sistemas abertos, os quais, por não poderem existir de forma isolada, interagiam com o ambiente, à semelhança dos seres vivos. Esses sistemas, de acordo com Daft (2005), configuram-se como um agrupamento de partes que guardam relações entre si, funcionando com o fim de atingir um propósito comum, e realiza-se mediante entradas, que, depois de transformadas, são devolvidas novamente ao ambiente. Tal interação que se dá por meio de cinco componentes: entradas; processos de transformação; saída; feedback; e o ambiente, conforme a Figura 1.

Figura1 - Visão de Sistemas das Organizações.

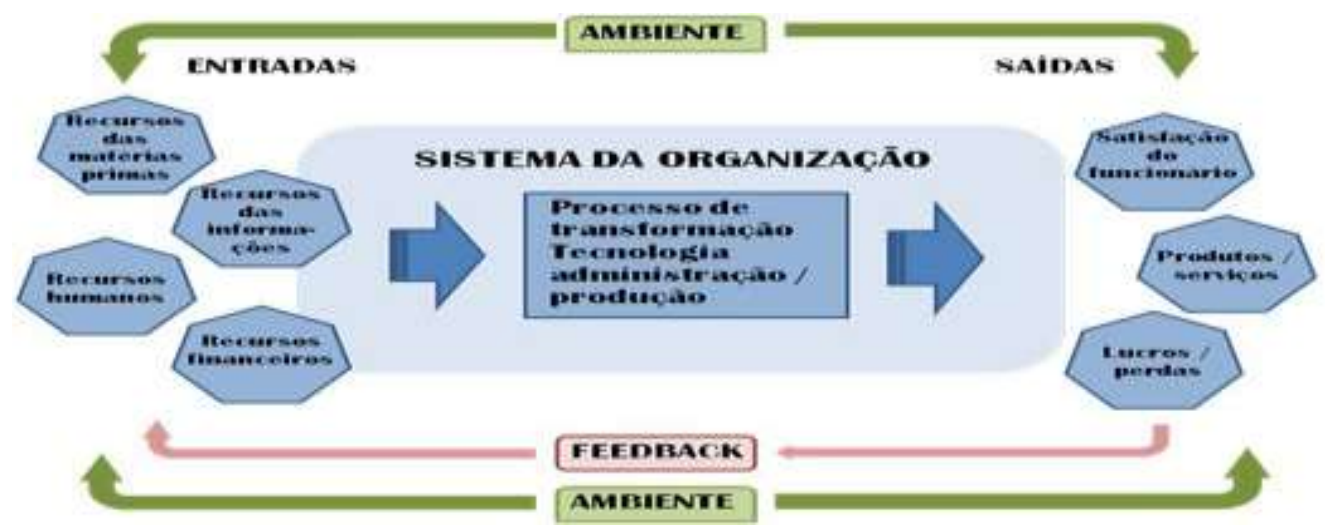

Fonte: Daft (2005, p.40).

Entradas são os recursos materiais, humanos, financeiros e informações, empregados para produzir bens ou serviços. Processo de transformação é a ação tecnológica de produção que converte entradas em saídas. Essas, por sua vez, incluem os produtos e/ou serviços da empresa. Feedback é o conhecimento dos resultados que vão orientar as seleções dos novos processos. Por fim, tem-se o ambiente de inserção da organização, que inclui forças sociais, econômicas, políticas e tecnológicas.

Sistema aberto, orgânico, desburocratizado ou adhocrático, conforme Mintzberg, Ahlstrand e Lampel (2010) e Cury 
(2007), é um sistema fundamental para organizações mais instáveis, que passam por permanentes transformações. As tarefas perdem em formalização, porque devem ser continuamente redefinidas por causa da interação, tanto verticais como lateralmente, com outros funcionários. Esse novo ambiente, como observam Mendes e Guimarães (2002), exige organizações mais flexíveis, dotadas de maior habilidade de reação em ambientes complexos, com capacidade de antever as mudanças e ter condições de respondê-las com maior rapidez. Costa, Souza e Fell (2012), em seu estudo com o objetivo de propor um novo modelo de estrutura organizacional, evidenciaram, por meio de pesquisa bibliográfica, a evolução de modelos de gestão mais flexíveis e dinâmicos, resultantes das respostas cada vez mais rápidas às mudanças e demandas da sociedade. Todo esse processo evolutivo organizacional afetou também as organizações em sentido público, as quais passaram a revisar as estruturas em busca de maior desenvolvimento e efetividade dos serviços.

As organizações públicas surgiram com vistas à satisfação da sociedade, em especial, as demandas coletivas. Nesse sentido, "o aparelho de Estado é o Estado como organização, que conta com servidores públicos, recursos financeiros, máquinas, equipamentos e instalações, para a prestação de serviços no interesse da sociedade" (BRASIL, 1997, p.15). Segundo Lima (1994), essas organizações têm, como obrigação estatal, oferecer serviços sociais de qualidade à população e garantir os direitos inerentes à cidadania. Kanaane, Fiel Filho e Ferreira (2010) entendem que seu funcionamento se pauta na conformidade da obediência dos princípios constitucionais e legais, com a devida observância equilibrada do bom senso.

Dessa forma, a fim de aperfeiçoar os serviços prestados pelo Estado à população, também evoluíram com o tempo, experimentando três modelos: o patrimonialista; o burocrático e o gerencial (conhecido como nova gestão pública). Ao longo da história brasileira, esses modelos se sucederam, segundo Brulon, Ohayon e Rosembeg (2012), sem que, contudo, nenhum deles tivesse sido abandonado, com o ensejo de introduzir conceitos mais modernos, superar deficiências e eliminar a apropriação particular da coisa pública.

Segundo Bresser-Pereira (1996) e Faoro (2001), a administração patrimonialista foi um modelo de gestão herdado da cultura portuguesa, e é típico de monarquias absolutistas nas quais o patrimônio público e o privado se confundem. De início, ao se instalarem no Brasil, criaram organizações e cargos com o objetivo de agraciar quem se havia sacrificado pelas autoridades. 
O avanço administrativo e judicial, em relação ao período colonial, provocou um grande impacto social, cultural, político e econômico no país, consolidando o estado nacional. Com o progresso administrativo local, segundo Gomes e Oliveira (2010), a administração do Estado concentrou-se na pessoa do rei. Esse modelo de gestão foi caracterizado por nepotismo, favoritismo, privilégios, paternalismo e pela corrupção. Críticas não faltaram ao autoritarismo e à centralização, acabando por ser substituído pelo modelo burocrático, na década de 1930.

O modelo administrativo burocrático, de acordo com Secchi (2009), desfrutou notável disseminação nas administrações públicas durante o século $\mathrm{XX}$ em todo mundo. Embora o surgimento remonte ao século XVI, o autor recorda que a inserção nas organizações públicas e privadas se deu apenas no século XX. Consoante Costa (2008), o Estado precisava se transformar, a fim de que fosse possível atender à necessidade de um impulsionador da máquina pública. A administração pública adotou, assim, uma forma racional-legal de dominação e poder, descrita por Weber (2012), como a que se legitima a partir do comando que emana das normas e do tipo formal das instituições estabelecidas, e não mais pela imposição real e das tradições.

Dessas evidências, brotam, como observa de Secchi (2009), as três características fundamentais do modelo burocrático público, quais sejam a formalidade, a impessoalidade e o profissionalismo, descritas no Quadro 1.

Quadro 1 - Características do Modelo Burocrático.

\begin{tabular}{|c|l|}
\hline Características & \multicolumn{1}{|c|}{ Descrição } \\
\hline Formalidade & $\begin{array}{l}\text { Deveres e responsabilidades funcionais e organizacionais; configuração e legitimação da hierarquia } \\
\text { administrativa; normas e procedimentos administrativos; formalização da decisão e da } \\
\text { comunicação; divisão da tarefa bem definida e padronização das rotinas. }\end{array}$ \\
\hline Impessoalidade & $\begin{array}{l}\text { As posições hierárquicas pertencem às organizações, não às pessoas e suas atuações estão } \\
\text { estabelecidas em normas e leis, atentando estritamente à finalidade pública. }\end{array}$ \\
\hline Profissionalismo & $\begin{array}{l}\text { Ligado ao valor positivo do mérito, ocupam o cargo os melhores em capacidade técnica e em } \\
\text { conhecimento (prática contrária ao nepotismo); separação entre o público e o privado; remuneração } \\
\text { pelo trabalho; divisão racional das tarefas e do trabalho e separação dos ambientes trabalho e } \\
\text { residência. }\end{array}$ \\
\hline
\end{tabular}

Fonte: Elaborado pelo autor, adaptado de Secchi (2009).

Na administração pública brasileira, segundo Brulon, Ohayon e Rosenberg (2012), a burocracia passou por algumas etapas de reformas. A primeira delas compreendeu o 
período de 1930 a 1963, durante o qual foi criado o Departamento de Administração do Serviço Público (DASP) com a função de racionalizar os métodos administrativos, criar o mérito, revisar a estrutura organizacional e fazer o uso planejado do orçamento público. $\mathrm{Na}$ segunda, de 1964 a 1985, a reforma cobrou maior agilidade e flexibilidade do Estado desenvolvimentista. Reduziu-se a atuação do DASP, descentralizando a máquina administrativa em administração direta e indireta, e transferindo algumas atividades para a iniciativa privada, além de mudar o regime trabalhista dos servidores públicos de estatutário para celetista. A terceira, de 1986 a 1988, caracterizou-se pela exigência feita pela sociedade para a redução dos gastos públicos e o estabelecimento de mecanismos de eficiência na gestão pública. Extinguiu-se, assim, o DASP e criou-se a Secretaria de Administração Pública da Presidência da República (SEDAP), dando início, então, à racionalização e à contenção de gastos públicos, à formulação de políticas de pessoal e a um processo mais eficaz de estrutura da administração federal. A última, delineada pela promulgação da Constituição do Brasil de 1988, viu-se apegada ainda às normas, mas assegurando maiores garantias de direitos ao cidadão e limitando a amplitude dos poderes do Estado, tornando-se a mais administrativa das constituições.
Entretanto, o modelo burocrático, mesmo buscando melhor forma de administrar a coisa pública de forma eficiente e eficaz, conforme observa Silva (2011), também foi alvo de duras críticas, na medida em que rigidez, excesso de normas e procedimentos, autoritarismo e centralização da decisão, resistência às mudanças, ausência de empreendedorismo e inflexibilidade tornam-na uma administração pública ineficiente para o contexto social. A falta de legitimidade da administração burocrática perante a sociedade, conhecida como Estado burocrático, a crescente demanda da pauta de problemas sociais e a diferenciação de estruturas complexas, aliadas às fragilidades do Estado para resolver os problemas, segundo Bresser-Pereira (1996) e Abrucio (1997), fizeram com que surgisse um novo modelo público de administração da coisa pública, denominado de gerencial, inspirado nos princípios da administração privada.

Essa nova forma de administração pública apareceu como resposta à crise internacional do aparelho do Estado na segunda metade do século XX, quando a Europa e os Estados Unidos perceberam a expansão econômica de alguns países no mercado internacional. Buscando constante redução de custos, qualidade de serviços e tendo o cidadão como beneficiário, o Estado passou, então, a ser orientado pelos princípios de eficiência e qualidade da gestão da coisa 
pública (BRASIL, 1995; SECCHI, 2009). Paes de Paula (2005), constata que, embora esse modelo tenha se desenvolvido no ambiente europeu e americano, ganhou força e se espalhou pelo mundo, passando a representar as necessidades de empresas e governos. O gerencialismo no Brasil iniciouse, conforme Costa (2008) e Motta (2013), com o então presidente Collor, quando começou a introduzir os princípios da new public management (NPM). Esse modelo objetivava instituir na gestão pública a operacionalização das instituições privadas, e ganhou força a partir dos anos 1990, no governo de Fernando Henrique Cardoso. O ex-presidente, por meio de reforma administrativa, buscou solucionar os problemas da baixa qualidade da gestão burocrática, combater a crise fiscal, promover o ajuste fiscal, ganhar eficiência, reduzir custos e diminuir a máquina pública.

Nesse período, foi criado o Ministério da Administração e Reforma do Estado. Para a pasta foi nomeado Luiz Carlos BresserPereira, que optou trazer ao Brasil o modelo britânico, adaptando-o à realidade nacional. Com o órgão, foram colocados em prática os níveis em que se dividem os setores do Estado, visualizados no Quadro 2.

Quadro 2 - Níveis de Divisão dos Setores do Estado.

\begin{tabular}{|c|c|l|}
\hline Setor & Tipo de Organização & \multicolumn{1}{c|}{ Características } \\
\hline Núcleo Estratégico & $\begin{array}{c}\text { Legislativo, Judiciário, } \\
\text { Presidência da República, } \\
\text { Ministérios. }\end{array}$ & $\begin{array}{l}\text { Órgãos nos quais as decisões estratégicas são tomadas, criam-se as } \\
\text { leis e se cobra o cumprimento delas. }\end{array}$ \\
\hline $\begin{array}{c}\text { Atividades } \\
\text { Exclusivas }\end{array}$ & $\begin{array}{c}\text { Policial, regulamentação, } \\
\text { fiscalização, seguridade, } \\
\text { fomento. }\end{array}$ & Serviços prestados apenas pelo Estado. Poder extroverso. \\
\hline $\begin{array}{c}\text { Serviços não } \\
\text { Exclusivos }\end{array}$ & $\begin{array}{c}\text { Universidades, Hospitais, } \\
\text { Centro de Pesquisas, } \\
\text { Museus. }\end{array}$ & $\begin{array}{l}\text { Serviços que o Estado oferece simultaneamente com outras } \\
\text { organizações públicas não estatais e mercado privado. As } \\
\text { instituiçôes desse setor não possuem poder de Estado, estão } \\
\text { presentes para garantir direitos fundamentais, sem visão de lucro. }\end{array}$ \\
\hline $\begin{array}{c}\text { Produção de Bens } \\
\text { e Serviços para o } \\
\text { Mercado }\end{array}$ & Empresas Estatais & $\begin{array}{l}\text { Atividades com fins lucrativos. Estão nessa condição ou porque } \\
\text { faltou capital privado ou por necessidade de prestação de serviço ao } \\
\text { cidadão. }\end{array}$ \\
\hline
\end{tabular}

Fonte: Adaptado pelo autor do documento do Plano Diretor da Reforma do Aparelho do Estado (BRASIL, 1995, p. 41-42).

A nova organização administrativa, para Bresser-Pereira (1996), teve como objetivo ser estratégica, voltada para os meios da administração pública, reduzindo os custos, aumentando a qualidade da prestação dos serviços e gerando benefícios para os cidadãos. As características do modelo gerencial são agilidade, descentralização e 
desconcentração, controle de resultados, flexibilidade, profissionalismo e horizontalização das estruturas (LOSEKANN; SALDANHA, 2007).

Os modelos patrimonialista, burocrático e gerencialista da gestão pública brasileira influenciaram significativamente na construção de estruturas organizacionais de prestações de serviços. Contudo, mesmo sendo um avanço, o modelo atual ainda guarda a presença da apropriação privada do bem público e da rigidez da norma, o que o faz prestar o serviço idealizado ainda de forma não completamente cidadã, conforme ressalta Motta (2013).

Infelizmente, como lembram Santos e Souza (2008), é consenso que as organizações públicas sejam vistas como ineficientes e improdutivas. Consoante reflexão de Brulon, Ohayon e Rosembeg (2012), ao buscarem informações sobre a implementação da reforma brasileira, com finalidade de detectar prováveis fragilidades na reforma gerencial, obtiveram como resposta dificuldades de ajustamento ao novo e resistência à imposição da reforma gerencial. Motta (2013) esclarece, ao verificar o estado da arte da gestão pública, que esses problemas estão intimamente ligados principalmente à falta de dinamicidade na alteração das normas do estado e ao apego político e indisposição às atividades administrativas por parte dos gestores. Também observou que a sensação que se tem é que o Estado, mesmo com inovações, está sempre no recomeço, num caminho aparentemente pouco percorrido.

Assim, conforme Mintzbeg (2006) e Picchiai (2010), as organizações, a fim de que possam atingir os objetivos e garantir atendimento eficiente e de qualidade, recorrem aos elementos e mecanismos de coordenação institucionais, para melhor ajustamento da configuração organizacional. Para tanto, como observa Motta (2013), é indiscutível a necessidade de planejamento e ação com olhar globalizante e consciente em relação aos fatores e perspectivas que envolvem a administração pública. A esse trabalho, executado pelo analista organizacional, dá-se o nome de estrutura organizacional.

\section{Estrutura Organizacional}

Pode-se afirmar que estrutura é fator crucial para garantir condições apropriadas da organização. É nela que se definem atividades, recursos para execução, pessoas para as atividades, competência e limite de alçadas. A configuração estrutural funciona, portanto, como instrumento básico e essencial para o desenvolvimento e a implementação do plano organizacional nas instituições, desenhada de acordo com a missão e visão estabelecidas, com a finalidade de alcançar o que se almeja: 
o instrumento administrativo resultante da identificação, análise, ordenação e agrupamento das atividades e dos recursos das empresas, incluindo $\mathrm{o}$ estabelecimento dos níveis de alçada e dos processos decisórios, visando ao alcance dos objetivos estabelecidos pelos planejamentos das empresas (OLIVEIRA, 2006, p.69).

Estrutura organizacional, segundo Costa, Souza e Fell (2012), é algo imprescindível, independentemente do tamanho, de modo que toda corporação precisa de uma composição que funcione como ferramenta de controle por meio da distribuição de cargos, das relações interpessoais, do planejamento dos objetivos e metas, a fim de facilitar o ajuste organizacional e levar as pessoas a se responsabilizarem por um funcionamento o mais adequado e eficiente possível da organização.

Cury (2007) entende que, para o ajustamento da estrutura, se faz necessária a análise de três variáveis, conforme o que se constata no Quadro 3:

Quadro 3 - Modelo de Análise de Ajustamento da Estrutura.

\begin{tabular}{|c|l|}
\hline Análise das & \multicolumn{1}{|c|}{ Descrição } \\
\hline Atividades & $\begin{array}{l}\text { Possibilita a adequada análise e posterior construção da estrutura intimamente ligada aos objetivos } \\
\text { organizacionais. }\end{array}$ \\
\hline Decisões & $\begin{array}{l}\text { Mostra qual estrutura de alta administração é necessária à organização e que autoridade e } \\
\text { responsabilidade devem ter os diferentes níveis de gerência operacional. }\end{array}$ \\
\hline Relações & $\begin{array}{l}\text { Aponta relações de cima para baixo e prioriza a relação de baixo para cima e valoriza as relações } \\
\text { laterais, importante contribuição que o gerente dá aos gerentes de outras atividades. }\end{array}$ \\
\hline
\end{tabular}

Fonte: Elaborado pelo autor, adaptado de Cury (2007).

Uma estrutura adequada, de acordo com Oliveira (2006), faz com que a instituição se revista de uma série de benefícios, tais como: identificação das tarefas necessárias; organização das funções e responsabilidades; informações, recursos e feedback aos empregados; medidas de desempenho compatíveis com os objetivos e condições motivadoras de trabalho. Assim, torna-se foco de constante readequação da estrutura, revelando segundo Mintzberg, Ahlstrand e Lampel (2010), o ciclo de vida da instituição.
No entanto, alertam Patini, Figueira e Fernandes (2010), que não basta 'ajustar por ajustar'. É pertinente considerar a coerência entre o ajuste realizado e as necessidades da organização. Em um estudo de caso, com objetivo de mostrar uma mudança de estrutura realizada em uma multinacional instalada no Brasil, em 2007, os autores constataram que a decisão de readequação, adotada pela equipe gestora, não considerou os propósitos organizacionais, nem o devido cuidado com as pessoas envolvidas. A Instituição fora reestruturada para operar sem o antigo diretor presidente, de forma a todos os gerentes e 
diretores participarem do poder decisório e executivo e estarem diretamente subordinados à sede nos Estados Unidos. O resultado gerou uma série de conflitos, provocando descontentamento geral e vários pedidos de demissão. Houve um desalinhamento de propósito, verificando-se divisão e antagonismo entre empresa e empregados, culminando com dúvida sobre o futuro da organização.

Veloso e Trevisan (2010) chamam a atenção para o fato de que, mesmo sendo a estrutura decorrente de uma estratégia, nem sempre poderá ser assim. Ao realizarem um estudo de caso, em uma agência bancária de um banco nacional privatizado, com $\mathrm{o}$ objetivo de descrever as mudanças estruturais ocorridas no ano de 2004, verificaram que em alguns casos, haverá organizações que serão influenciadoras de estratégias. Essa é a situação, por exemplo, das organizações públicas que, por suas características particulares de estabilidade, oferecem impossibilidades e resistências. Os autores inferiram, então, que o ideal é que a estrutura seja delineada em função do trabalho e das pessoas, do fluxo de comunicação e dos processos.

Nesse sentido, para o desenvolvimento da estrutura, considerar-se-á formalidade, desdobrada em componentes, condicionantes, níveis de influência e abrangência, conforme entendimento de Oliveira (2006), Mintzberg
(2006) e Cury (2007), para a obtenção de uma consistência interna e situacional da organização.

\subsection{Formalidade Organizacional}

Uma estrutura organizacional, quanto ao grau de formalização, pode ser classificada em formal ou informal. Conforme Vasconcellos (1989) e Oliveira (2006), vários são os condicionantes que concorrem para inviabilizar a premissa de que organizações operam apenas por meio da estrutura formal, a saber: é praticamente impossível elaborar um conjunto de normas que cubra todas as possíveis situações; há urgência de soluções rápidas que respondam a situações críticas relacionadas à liderança e objetivos pessoais, e influam de maneira intensa na operação da estrutura, mesmo não aparecendo no organograma. Assim, muitas vezes a organização opera de forma diferente da estabelecida, dando origem à estrutura informal.

Estruturas formais foram criadas para que as organizações possam dividir e executar as funções administrativas: planejar; organizar; dirigir e controlar. São essas que permeiam todos os níveis organizacionais, começando pelo estratégico e descendo até o operacional. Para Castro e Teixeira (2009), a organização deve se revestir de formalidade, tendo em vista a manutenção da vida. Porém, 
essa rigidez, conforme Cury (2007), quase sempre condicionada pelo comportamento e pelas relações apresentadas pelos membros da corporação, faz com que surja a denominação organização informal, não permitindo que as estruturas reflitam uma imagem fiel da organização, provocando prejuízos corporativos. Foi o que revelou o estudo de caso de abordagem qualitativa realizado por Grzeszczeszyn e Vieira (2012), ao confrontar a imagem dos gestores e a dos consumidores, constatando que as organizações precisam se preocupar com seu retrato, uma vez que favorece as relações com fornecedores $\mathrm{e}$ influencia a procura dos serviços e por parte dos clientes. Para Chernatony (2005), a imagem positiva gera credibilidade e, em alguns casos, um valor extra agregado ao produto ou serviço, por meio da marca.

Diante disso, a distinção que geralmente se faz entre organização formal e informal é que, enquanto a primeira é planejada, a segunda se constitui a partir do impacto das personalidades dos atores sobre as funções que lhes foram destinadas. Assim, não existe organização puramente formal sem sua contrapartida. O ideal, segundo Oliveira (2006), é que haja perfeita interação entre os dois tipos de formalidade na organização.

Castro e Teixeira (2009), ao realizarem um estudo de caso numa clínica oftalmológica, a qual concentrava várias especialidades relacionadas à oftalmologia, conheceram os problemas pelos quais passava a organização, e optaram por fazer um diagnóstico situacional. Logo, constataram que a empresa operava basicamente na informalidade. Propuseram, então, um novo modelo, mais formal, configurando-a como uma 'estrutura em rede', apresentada por Quinn, Anderson e Finkelstein (2001). Na estrutura proposta, os pesquisadores evidenciaram a separação entre área administrativa e coordenação médica, o que resultou em maior produtividade. Assim, mesmo que a informalidade esteja presente, pelas características individuais das pessoas, são os elementos formais, como considera Barbalho (2012), que definem a estrutura.

No entendimento de Oliveira (2006), quatro são os sistemas componentes da organização: responsabilidade; autoridade; comunicação e decisão. Isto é, análises das atividades, decisões e relacionamentos intraorganizacional.

A responsabilidade pode ser entendida como o dever de um funcionário desempenhar uma tarefa que lhe foi atribuída pelo superior. Correlaciona-se, segundo Oliveira (2006), à situação do subordinado em assumir a obrigação e prestar contas ao superior. Para Daft (2005), os funcionários geralmente recebem autoridade na medida de suas responsabilidades. Se for pequena, pode ser difícil a condução. Sendo excessiva, o gestor pode se tornar um tirano, levando a resultados 
supérfluos. Os aspectos básicos desse sistema são departamentalização, linha e assessoria e especialização do trabalho.

A departamentalização é, talvez, o componente mais conhecido pelos funcionários de uma organização. Segundo Oliveira (2006, p.101), “é o agrupamento, de acordo com um critério específico de homogeneidade, atividades e correspondente recursos (humanos, financeiros, materiais e equipamentos) em unidades organizacionais", e caracteriza-se pela divisão do trabalho por especialização dentro da estrutura organizacional.

Em relação à atividade de linha e assessoria, a atividade em linha está ligada à operacionalização da organização, na qual as pessoas, em posições administrativas, têm autoridade formal para dirigirem e controlarem subordinados imediatos, de acordo com as funções da organização. Por sua vez, a atividade em assessoria se refere às atividades de análise, estudos de novos negócios e aconselhamentos, e inclui o direito de advertir, recomendar e aconselhar na área da respectiva especialidade do assessor no quadro de funcionários. Essa atividade de assessoria ainda se caracteriza, conforme Cury (2007), pela valoração da especialização ou pela multiplicidade de contatos entre os supervisores e operadores, ou ainda pela divisão do trabalho, execução e supervisão. Quanto à aplicação na estrutura, Daft (2005) verifica que a linear tem larga aplicação nas organizações burocráticas e de alto grau de formalização. A de assessoria aplica-se, com maior frequência, nas organizações industriais, como as de operários de linha de produção.

Desse sistema de responsabilidade, surge a especialização do trabalho. Sabe-se, segundo Daft (2005), que as organizações realizam uma grande variedade de tarefas, entendidas como divisão de mão de obra. A especialização culminará na distribuição de atividades pelas unidades organizacionais, conforme Oliveira (2006), seguindo os critérios da natureza, similaridade e complementaridade. O sistema, dessa forma, precisa se caracterizar pela qualidade de trabalho e busca constante de resultados, procurando formalização da divisão do trabalho e das atividades; responsabilidade e coordenação.

No entanto, mesmo com esse aparente benefício da especialização, Daft (2005) constata que os funcionários ficam muito isolados e fazem um único serviço, perdendo a visão de conjunto. Por conta disso, muitas organizações vêm se afastando do princípio de especialização, aumentando os desafios para seus funcionários, e até constituindo equipes para as tarefas, fazendo-as circular pelas diversas etapas do trabalho, por entender, conforme Castro e Teixeira (2009), que se trata de um momento atual de 
imprevisibilidade, requerendo maior flexibilidade da estrutura.

O sistema de autoridade, ou de comando, ou de cadeia de comando, segundo Daft (2005), é um sistema que funciona em linha ininterrupta de autoridade. Nele existem dois princípios básicos de autoridade: unidade escalar e princípio escalar. O primeiro é a linha de autoridade formal em uma organização, cada funcionário se reporta a apenas a um supervisor. O segundo, conforme Daft (2005, p. 224), se refere "a uma linha claramente definida de autoridade na organização que inclui todos os funcionários". Verifica-se, assim, toda a cadeia de relações de autoridade de um superior para com o subordinado, da base ao topo da organização.

$\mathrm{Na}$ cadeia de comando, autoridade é entendida como o direito formal e legítimo do superior para tomar decisões, ditar regras e ordens, além de reservar os recursos necessários, que proporcionem de valores únicos, conforme Mintzberg, Ahlstrand e Lampel (2010), para atingir os objetivos da organização. Por isso, não se pode deixar de considerar os tipos de autoridade: o hierárquico, o que segue as linhas de comando da organização; e o funcional, estabelecido pelas funções básicas exercidas pela unidade organizacional. Contudo, Oliveira (2006a), Veloso e Trevisan (2010), Patini, Figueira e Fernandes (2010) recordam que essa autoridade deve ser bem estabelecida, a fim de evitar duplicidade e confusão de comando, sugerindo à autoridade funcional apenas o estabelecimento de políticas administrativas. Os aspectos básicos do sistema em questão, no entendimento de Oliveira (2006), seriam delegação, centralização e descentralização, níveis hierárquicos e amplitude administrativa.

A delegação pode ser entendida, como "processo de transferência de determinado nível de autoridade de um chefe para seu subordinado, criando o correspondente compromisso pela execução da tarefa delegada" (OLIVEIRA, 2006, p.189). Os elementos básicos da delegação podem ser assim apresentados: a tarefa que foi transferida do chefe para o subordinado, e a contrapartida responsável do subordinado com o chefe de cumprir a tarefa transferida. Para a adequada implantação, Daft (2005), Oliveira (2006), Patini, Figueira e Fernandes (2010), sugerem, dentre outras, algumas premissas: a autoridade deve ser delegada até o limite da medida necessária de sua efetiva realização e proporcional ao cargo ou função; a designação deve ser precisa, entendida e aceita de forma clara; a comunicação necessita ser estabelecida e aberta com o subordinado. Oliveira (2006) lembra que o fator que deve determinar a delegação é o desempenho total da organização e que se deve ficar atento aos obstáculos, tais como os 
medos de perder o poder e o de assumir responsabilidades.

Quanto à concentração da decisão da autoridade, essa pode ser centralizada ou descentralizada. Para Daft (2005, p. 226), “a centralização e a descentralização pertencem ao nível hierárquico no qual as decisões são tomadas”. Significa que, na centralização, a decisão da autoridade está mais perto do topo da hierarquia, enquanto que, na descentralização, acontece o inverso. Mintzberg (2006) entende que a decisão, em alguns casos, deve ser descentralizada. Explica que nem sempre a decisão pode ser levada ao centro sem que a informação se perca. Além de a quantidade de informação poder chegar a um volume considerável. Um dos grandes benefícios seria responder mais rápido às condições locais.

Por fim, tem-se a amplitude administrativa, também conhecida como amplitude de controle ou de supervisão, de acordo com Daft (2005), o número de funcionários que um superior consegue monitorar. Contudo, por não haver consenso em referência ao número de subordinados sob a responsabilidade de um mesmo chefe, o envolvimento com os liderados se torna fator determinante para definir este número. Isto deve ser equacionado com muito cuidado, para se evitar, por exemplo: perda de controle; ineficiência na comunicação; desmotivação, quando o número de pessoas for muito grande; ou ociosidade do chefe, falta de delegação e altos custos administrativos, quando o número for pequeno.

O resultado dessa divisão, conforme Daft (2005) e Mintzberg (2006), desemboca em altas estruturas, caracterizadas pelo estreitamento e número significativo de níveis hierárquicos, ou em baixas estruturas, mais largas, com poucos níveis hierárquicos. Os gerentes médios estarão mais próximos da base, a delegação de competência será mais igualitária, e maior será, assim, o nível de descentralização. Portanto, como o sistema de autoridade é o direito de dar ordens, exigir obediência ou mesmo a competência de executar o serviço, fatalmente seria prejudicado sem a efetiva presença da comunicação.

O sistema de comunicação, importante componente da estrutura organizacional, de acordo com Kunsch (2014), deve operar de forma a permitir que o fluxo de informações atinja todos os envolvidos dentro da instituição de maneira efetiva, pois são as pessoas que, ao comunicarem entre si, viabilizam o sistema (interação entre as partes), de forma que se garanta a sobrevivência e a consecução dos objetivos organizacionais no novo ambiente vivo de interação.

Oliveira (2006, p.79) define comunicação como "o processo interativo em que dados, informações, consultas e 
orientações são transacionados entre pessoas, unidades organizacionais e agentes externos à empresa”. Bueno (2005) e Kunsch (2014) entendem que, para tanto, implantação e exercício da comunicação organizacional devem ser adotados e praticados enquanto administração estratégica, a qual, segundo Crossan, Lane e White (1999), Bueno (2009) e Beltrame e Alperstedt (2015), se dá ao atingir toda organização e não apenas a uma pessoa ou grupo (por ser uma responsabilidade de todos), não desconsiderando fatores como: o novo ambiente; públicos de interesses; estabelecimento de uma cultura comunicacional, com canais de relacionamento; saberes, competências e experiências das pessoas.

Assim, para se estabelecer a estratégia de comunicação na organização, aos gestores faz-se necessário, consoante Torquato (2002), identificar e examinar os ruídos, ou seja, as barreiras que impedem a informação de circular e chegar, como desejada, ao destinatário. Nesse sentido, Chaves et al. (2010) orienta a sequência de alguns passos: saber o público alvo; definir a finalidade da comunicação; organizar a mensagem e escolher a melhor ferramenta de comunicação.

Segundo Daft (1997), essa transmissão pode se dar por meio de alguns canais principais, classificados em escala de riqueza: primeiro face a face, de modo que podem ser capturadas as expressões, linguagens não verbais, contribuindo para o entendimento, resposta e correções; depois, por meio telefônico ou meios eletrônicos, que embora percam as expressões visuais, mantêm o ganho do retorno rápido e a direção ao destinatário; por último, documentos escritos, dirigidos pessoalmente, os quais apresentam menos riqueza e retorno mais lento. Torquato (2002) e Kunsch (2003) ainda citam outros canais de interação interna, como, por exemplo, intranet e boletins.

Com relação à formalidade dos canais, Kunsch (2003) recorda que pode se dar de duas maneiras: formal, quando os meios são estabelecidos e planejados, derivadas da alta administração, seguindo o estabelecido na estrutura organizacional; e informais, como resultado das interpretações subjetivas dos atores, suplantando a formalidade. Embora não se considere menos importante, necessita-se, conforme Oliveira (2006), de controle rígido para não se dissipar informação importante. Esses canais, segundo Kunsch (2003), são os de abrangência intraorganizacionais ou internos. O autor lembra, ainda, que as instituições mantêm relações externas por meio de canais extraorganizacionais, salientando o fato de serem as organizações como organismos vivos.

Uma pesquisa realizada em 2005 pela consultoria Symnetics, constatou, como relata 
Barros (2005), que apenas 50\% dos gerentes se envolviam com administração estratégica no Brasil. Portanto, como observa Bueno (2005), mesmo que a comunicação venha ganhando detalhamento e espaço importantes nos últimos anos, o pensamento em relação a ela ainda a aponta como um gasto desnecessário e descartável, tornando difícil encontrar uma organização que tenha elaborado e colocado em prática uma gestão de comunicação plenamente efetiva.

A seguir, no Quadro 4, são apresentados, conforme Oliveira (2006), quatro aspectos básicos para o sucesso da comunicabilidade nas organizações.

Quadro 4 - Aspectos Básicos da Comunicação.

\begin{tabular}{|c|l|}
\hline Aspectos & \multicolumn{1}{c|}{ Características } \\
\hline $\begin{array}{c}\text { Esquema de } \\
\text { comunicação }\end{array}$ & $\begin{array}{l}\text { Podem ser de dois tipos: formal, quando planejada, controlada e facilitada conscientemente ou } \\
\text { informal, quando surge espontaneamente na organização. Essa pode ser boa ou ruim. Caberá à } \\
\text { organização criar mecanismos de amortização para diminuir os efeitos negativos, tendo em vista } \\
\text { não ser possível, como visto quando tratamos da formalidade da estrutura organizacional, operar } \\
\text { com apenas a formalidade na organização. }\end{array}$ \\
\hline $\begin{array}{c}\text { Fluxo de } \\
\text { comunicação }\end{array}$ & $\begin{array}{l}\text { A comunicação pode ser horizontal, quando entre unidades diferentes, porém no mesmo nível } \\
\text { hierárquico; diagonal, entre níveis e unidades diferentes e vertical, em níveis hierárquicos } \\
\text { distintos, contudo na mesma área de atuação. }\end{array}$ \\
\hline $\begin{array}{c}\text { Custo da } \\
\text { comunicação }\end{array}$ & $\begin{array}{l}\text { Entendendo que as comunicações são caras e demoradas, em alguns casos, o importante a se } \\
\text { considerar são as comunicações que levem a ações; logo, torna-se fundamental a administração } \\
\text { da comunicação. }\end{array}$ \\
\hline $\begin{array}{l}\text { Subsistema de } \\
\text { procedimento }\end{array}$ & $\begin{array}{l}\text { Dentro do sistema de comunicação, deve-se considerar como a organização vai definir quais } \\
\text { métodos serão utilizados e quais serão suas inter-relações, ou seja, as dependências, as sequências } \\
\text { e as tramitações. }\end{array}$ \\
\hline
\end{tabular}

Fonte: Elaborado pelo autor, adaptado de Oliveira (2006).

Portanto, a comunicação está presente na estrutura como componente indispensável, como afirma Kunsch (2014), a fim de que todos interajam e, assim, contem com informações claras e conscientes, para que seja possível a consecução dos objetivos organizacionais, em especial nas tomadas de decisões.

Acredita-se que não seja possível para uma organização deixar de tomar decisões. Contudo o administrador deve atentar para o fato de que tomar decisões não é simplesmente fazer escolhas dentre as disponíveis. Segundo Oliveira (2006, p.26) “decisão é a escolha entre vários caminhos alternativos que levam a determinado resultado". Leitão (1996) diz que as decisões não podem mais ser enfocadas apenas de modo particular, arbitrário e sem a devida análise das inúmeras relações. Precisam ser entendidas como um processo dinâmico e complexo do ambiente organizacional, no qual os atores interagem, influenciando e sendo influenciados, pois são parte dessa estrutura. Nesse sentido, a consultoria Symnetics, conforme Barros (2005), ao 
estudar a concentração da decisão nas empresas brasileiras, mostrou que os envolvidos diretamente com os trabalhos da organização, na sua grande maioria, não são considerados, de modo que, quando se tomam decisões na corporação, essas ficam a cargo de um grupo exclusivo de alta gerência.

Escolher adequadamente, na perspectiva do gerente, implica em: conhecimento prévio da instituição, das operações, mercados, fornecedores e políticas de governo; atenção aos elementos do processo, ou seja, à incerteza do ambiente que envolve a decisão e a valoração das consequências; e, ainda, a consciência dos recursos que são escassos e prejudicam a correspondente ação. Esse processo, segundo Moreno (2007), pode ser facilitado pelo conjunto de informações disponíveis nos arquivos organizacionais e por um Sistema de Informações Gerenciais (SIG), desenvolvido justamente para apoiar os administradores. Observa-se que uma organização produz e recebe uma quantidade enorme de informações, que levam os gestores a recorrer para o perfeito desempenho de suas funções. Informações, devidamente elaboradas, darão suporte às decisões organizacionais.

Assim, a composição da estrutura é formada pela colaboração destas quatro partes: sistema de responsabilidade, ao qual se atribui atividades; sistema de autoridade na distribuição do poder; sistema de comunicação para transmissão de informação; e sistema de decisões que conduza o gestor a fazer a escolha certa. Contudo, a estrutura não se ajusta apenas pelos seus componentes, pois também sofre influência de alguns condicionantes, tais como: pessoas; ambiente externo; objetivos, estratégias e políticas e natureza organizacional.

Acredita-se que a eficiência da estrutura organizacional depende do valor que se dá a estratégias para a execução das tarefas, enfatizando a importância da integração entre as pessoas e a satisfação ao realizarem essas tarefas. Segundo Patini, Figueira e Fernandes (2010), são as pessoas que asseguram os objetivos estabelecidos sejam alcançados conforme suas proposições. Por esse motivo, adverte Daft (2005), quando os funcionários não se sentem valorizados, também não se motivam a excelência e logo procuram outro ambiente que os possam sustentar. $\mathrm{O}$ autor reforça que muitos executivos, preocupados com essa fonte primária de vantagem competitiva, vêm enfatizando a necessidade de uma habilidosa administração de recursos humanos.

$\mathrm{O}$ processo de relacionamento da organização com o ambiente externo não pode deixar de ser apreciado. Entende-se por esse ambiente, conforme Mintzberg (2006), tudo o que está fora da organização: natureza; concorrência; posição geográfica. A avaliação da influência externa deve ser continuamente 
analisada e a estrutura deve ser aperfeiçoada, para o acompanhamento das variações ambientais, que fatalmente influenciarão a reorganização da estrutura. No entendimento de Costa, Souza e Fell (2012) e de Barbalho (2012), a organização atenta às condições externas percebe mais rapidamente as ameaças, como também, as oportunidades de crescimento organizacional, pois está aberta a mudanças, buscando melhor adequação aos processos organizacionais.

Os objetivos, estratégias e políticas são fatores que significam, segundo Kich e Pereira (2011), respectivamente, o alvo ao qual se pretende atingir e o critério ou orientação para a tomada da decisão. Assim, os autores entendem que, quando esses elementos estão delineados de forma clara, torna-se mais fácil estruturar a organização, porque se sabe o que esperar dos que a compõem.

Por fim, conforme Adizes (1996) e Patini, Figueira e Fernandes (2010), considera-se fator condicionante a natureza da própria organização, como: valores; história; pessoas que a compõem.

Desse modo, a complexidade e dinamicidade dos fatores condicionantes das organizações não podem ser ignoradas nem consideradas apenas na época da criação da organização. Precisam ser administradas, conforme ensina Mintzberg (2006), para o devido equilíbrio da estrutura no contexto de sua inserção. Assim como os elementos mencionados, os níveis de influência e abrangência também não podem estar ausentes, pois são determinantes do modelo organizacional.

Costumeiramente, segundo Oliveira (2006), os níveis de influência são divididos em três: estratégico; tático e operacional. Não se deve confundir, portanto, com a transferência de autoridade do sistema de comando, de modo que se trata da delegação de competência do maior para o de menor nível hierárquico, de maneira que o analista organizacional deve considerar se está estruturando o estratégico, tático ou operacional. Portanto, os modelos não serão exatamente iguais, pois cada um se correlaciona com o respectivo planejamento, o qual, segundo Daft (2005), incorpora os detalhes de meta e plano. O primeiro é o estado que se deseja atingir futuramente, o segundo é o esboço detalhado dos recursos e das ações necessárias para o alcance dos propósitos. Por conseguinte, planejamento significa determinar as metas organizacionais e definir as condições para atingi-las. Entende-se que começa com a missão formal, base para o nível estratégico, e que se desdobrará nos níveis tático e operacional.

No nível estratégico (alta gerência), consoante Oliveira (2006), o planejamento pode ser conceituado como um processo gerencial que possibilita ao executivo 
estabelecer o rumo a ser seguido pela organização, objetivando obter um nível de otimização de eficiência e eficácia. Nesse processo, se considera toda influência da estrutura organizacional e sua melhor interação com o meio. No tático (gerência média), há a parte que se desdobra e cumpre parcela do estrategicamente planejado, com o fim de aperfeiçoar as principais divisões, considerando as atividades homogêneas da organização. Por último, no operacional (gerência baixa), identificam-se as ações mais específicas e de curto prazo da instituição e criam-se as condições mais adequadas para a realização formal dos trabalhos diários.

Em relação ao nível de abrangência, a ação de modelagem pode ser desenvolvida a partir de três pontos de vista: da empresa, da unidade estratégica de negócio (UEN) e da corporação. O primeiro, o da empresa, considera toda a organização, tendo um ou mais negócios em seu contexto de atuação. $\mathrm{O}$ segundo, da unidade estratégica de negócio, realiza-se em termos de unidade estratégica de negócio, ou seja, "uma unidade ou divisão da empresa responsável para desenvolver uma ou mais Áreas Estratégicas de Negócios - AEN" (OLIVEIRA, 2006, p. 124). O terceiro, da corporação, considera a administração corporativa, a que reúne mais de uma AEN. Assim, para garantia de sucesso nas organizações públicas e ou privadas, torna-se imprescindível não somente a presença, mas, em especial, o alinhamento rigoroso dos elementos componentes da estrutura, influenciados pelos condicionantes e pela consideração da natureza organizacional (ADIZES， 1996; OLIVEIRA， 2006; MINTZBERG， 2006; CRUZ， 2007; VELOSO; TREVISAN, 2010).

\section{Considerações Finais}

O estudo permitiu apontar elementos para formulação da modelagem e revisão de estruturas organizacionais, quando necessário. Em um primeiro momento, procurou-se mostrar o contexto das organizações em geral e em âmbito público, e sua movimentação na história. Em seguida, definiu-se o fio condutor da pesquisa na perspectiva de Oliveira (2006), com sustentação em Vasconcellos (1989), Daft (2005), Cury (2007).

Dessa forma, descobriu-se que a organização, deve-se revestir de formalidade estrutural, congregando os sistemas componentes, condicionados e influenciados pelas pessoas, ambiente e natureza da organizacional de forma que possa dirigir e executar as atividades institucionais. Porém o analista organizacional deve estar atento ao fato que as organizações não funcionam apenas com base na formalidade. A informalidade também é percebida pela impossibilidade de as organizações 
normatizarem todas as situações, refletindo uma imagem diferente do desenho proposto.

Assim, embora a literatura aponte a informalidade como desestabilizadora de estruturas, constatou-se que é impossível eliminá-la totalmente, pois se faz presente pelos comportamentos e relacionamentos pessoais dos funcionários. O que se deve fazer, portanto, é tentar diminuir os efeitos negativos que proporciona a organização.

Ressalta-se, também, que o gestor deve entender ser o processo administrativo algo que não se encerra com intervenções pontuais, uma vez que as organizações sofrem constantemente pressão, devido às relações que mantém com o ambiente que as cerca e com os fatores que a acondicionam - o que requer, outrossim, permanente ajuste da estrutura organizacional e um olhar sobre o todo, e não apenas de forma parcial e esporádica.

Então, para se alcançar os objetivos estabelecidos pela instituição na razão de sua existência, é preciso considerar formalidades e informalidades, em sua justa medida, e os condicionantes diretamente relacionados à organização objeto de análise, levando em conta que seu sucesso se sustenta exatamente na arte de estruturar e modelar, sempre que necessário, tendo elementos claros como balizadores que sustentem a gestão quer seja de natureza pública ou privada.
Cabe salientar que as considerações discutidas neste trabalho não podem ser vistas como modelo acabado: é apenas um levantamento dos elementos julgados relevantes para a formulação e o ajustamento de estruturas organizacionais, segundo estudos recentes. Há diferentes pesquisas que se apoiam em teóricos com outro ponto de vista condutor, os quais apresentam elementos diversos, porém igualmente relevantes para a matéria. Para pesquisas futuras, sugere-se análise nas condicionantes das estruturas organizacionais públicas, tendo em vista a busca por flexibilidade.

\section{Referências}

\begin{abstract}
ABRUCIO, F. L. O impacto do Modelo Gerencial na Administração Pública: um breve estudo sobre a experiência internacional recente. Brasília: Escola Nacional de Administração Pública, Cadernos ENAP, n. 10, p. 1-50, 1997. Disponível em <http://www.enap.gov.br/downloads/ec43ea4f Abrciocad\%2010.pdf >. Acesso em: 06 nov. 2014.
\end{abstract}

\section{ADIZES, I. Os ciclos de vida das organizações. São Paulo: Pioneira, 1996.}

BARBALHO, C. R. S. Estrutura Organizacional de Bibliotecas Universitárias: Subsídio para sua Composição. SNBU XVII, p. 1-14, 2012. Disponível em <http://www.snbu2012.com.br/anais/pdf/4RE Z.pdf>. Acesso em: 10 mar. 2015.

BARROS, G. Empresas brasileiras concentram decisões. Folha de São Paulo, São Paulo, p. B3, 25 set. 2005. Disponível em 
<http://www1.folha.uol.com.br/fsp/dinheiro/fi 2509200506.htm>. Acesso em: 17 nov. 2014.

BERTALANFFY, L. V. Teoria geral de sistemas. 2. ed. Petrópolis: Vozes, 1975.

BELTRAME, M. M. L. L.; ALPERSTEDT, G. D. Construção de política de comunicação em instituições de educação profissional, científica e tecnológica: uma proposta com base na experiência do IFSC. Navus -

Revista de Gestão e Tecnologia, v. 5, n. 2, p. 14-26, 2015. Disponível em < http://navus.sc.senac.br/index.php/navus/articl e/view/224/215>. Acesso em: 20 out. 2015.

BRASIL. Ministério da Administração e Reforma do Estado. Plano Diretor da Reforma do Aparelho de Estado. Brasília, 1995. Disponível em <http://www.bresserpereira.org.br/documents/ mare/planodiretor/planodiretor.pdf $>$. Acesso em: 12 nov. 2014.

. Ministério da Administração Federal e Reforma do Estado. A reforma do aparelho do estado e as mudanças constitucionais: síntese \& respostas a dúvidas mais comuns. Cadernos MARE, n. 6. Brasília: Mare, 1997. Disponível em

<http://www.bresserpereira.org.br/documents/ mare/cadernosmare/caderno06.pdf $>$. Acesso em: 14 nov. 2014.

BRESSER PEREIRA, L. C. Da

Administração Pública Burocrática à Gerencial, Revista do Serviço Público, ENAP, v. 120, n.1, p. 1-28, 1996. Disponível em

<http://www.bresserpereira.org.br/papers/199 6/95.AdmPublicaBurocraticaAGerencial.pdf> . Acesso em: 16 nov. 2014.

BRULON, V.; OHAYON, P.; ROSENBERG, G. A reforma gerencial brasileira em questão: contribuições para um projeto em construção. RSP - Revista do Serviço Público, v. 63, n.3, p. 265-284, 2012. Disponível em <http://seer.enap.gov.br/index.php/RSP/articl e/view/99>. Acesso em: 16 nov. 2014.
BUENO, W. C. A comunicação Empresarial Estratégica: Definindo os Contornos de um Conceito. Conexão - Comunicação e Cultura, UCS, v. 4, n. 7, p. 11-20, 2005. Disponível em

http://www.ucs.br/etc/revistas/index.php/cone xao/article/viewFile/146/137. Acesso em: 11 out. 2014.

. Comunicação empresarial:

políticas e estratégias. São Paulo: Saraiva, 2009.

CASTRO, V. A.; TEIXEIRA, T. R. B. A. Estrutura Organizacional em Rede para Clínicas Oftalmológicas. Revista CEPPG, ano XI, n. 20, p. 55-69, 2009. Disponível em <http://www.portalcatalao.com/painel_cliente s/cesuc/painel/arquivos/upload/temp/95fd22b 99dbb4b8ee75dc2b39db68b78.pdf>. Acesso em: 09 out. 2014.

CHAVES, L. E.; NETO, F. H. S.; PECH, G.; CARNEIRO, M. F. S.: Gerenciamento da comunicação em projetos. $2^{\mathrm{a}}$. Ed. - Rio de Janeiro: Editora FGV, 2010.

CHERNATONY, L. Construção de marca. In: BAKER, M. J. (Org.). Administração de marketing. Rio de Janeiro: Elsevier, p. 263279, 2005.

\section{COELHO, F. U. Manual de direito comercial. São Paulo: Saraiva, 2004.}

COSTA, F. L. Brasil: 200 anos de Estado, 200 anos de administração pública, 200 anos de reformas. Revista de Administração Pública, v. 42, n. 5, p. 829-874, 2008. Disponível em <http://www.scielo.br/pdf/rap/v42n5/a03v42n 5.pdf>. Acesso em: 09 out. 2014.

COSTA, M. C. F.; SOUZA, B.S.S.; FELL, A.F.A. Um Estudo da Estrutura Organizacional e as Mudanças Organizacionais: Proposta de Um Novo Modelo. Navus - Revista de Gestão e Tecnologia, v. 2, p. 57-74, 2012. Disponível em 
<http://navus.sc.senac.br/index.php/navus/arti cle/view/62/40>. Acesso em: 15 out. 2014.

CROSSAN, M. M.; LANE, H. W.; WHITE, R. E. An Organizational Learning Framework: From Intuition to Institution. The Academy of Management Review, v. 24, n. 3, p. 522-537, 1999. Disponível em <http://www.jstor.org/stable/259140?seq=1\#p age_scan_tab_contents $>$. Acesso em: 21 out. 20145.

\section{CRUZ, T. Sistema, Organização e Métodos:} estudo integrado das novas tecnologias de informação. $-3^{\text {a }}$. ed. -4 . Reimpr. - São Paulo: Atlas, 2007.

CURY, A. Organização e métodos: uma visão holística. - 7. ed. rev. e ampl. - São Paulo: Atlas, 2007.

DAFT, R. L. Administração. 4.ed. São Paulo: LTC, 1997.

. Administração. 6. ed. São Paulo:

Pioneira Thomson Learning, 2005.

FAORO, R. F. Os donos do poder: formação do patronato político brasileiro. 3. ed. rev. São Paulo: Globo, 2001.

GOMES, M. L. S. G.; OLIVEIRA, F. C. Modelos organizacionais de administração pública: um estudo dos aspectos da realidade cearense na estrutura de referência das reformas do Estado. Revista de Ciências da Administração, v. 12, n. 28, p. 105-126, 2010. Disponível em

<https://periodicos.ufsc.br/index.php/adm/arti cle/view/2175-

8077.2010v12n28p105/17427>. Acesso em: 17 nov. 2014.

GRZESZCZESZYN, G.; VIEIRA, F. G. D. Imagem organizacional: Uma Análise Comparativa da Imagem Desejada por Supermercados e da Imagem Percebida por Consumidores. Qualitas Revista Eletrônica, v. 13, n. 2, p. 1-14, 2012. Disponível em $<$ http://revista.uepb.edu.br/index.php/qualitas/ article/view/1508/852>. Acesso em: 02 out. 2015.

KANAANE, R.; FIEL FILHO, A.; FERREIRA, M. G. Gestão pública: planejamento, processos, sistemas de informação e pessoas. São Paulo: Atlas, 2010.

KICH, J. I. F.; PEREIRA, M. F. A influência da liderança, cultura, estrutura e comunicação organizacional no processo de implantação do planejamento estratégico. Cad. EBAPE.BR [online]. 2011, vol.9, n.4, p. 1045-1065.

Disponível em

<http://bibliotecadigital.fgv.br/ojs/index.php/c adernosebape/article/view/5233>. Acesso em: 13 nov. 2014.

KUNSCH, M. M. K. Planejamento de relações públicas na comunicação integrada. $4^{\text {a }}$. ed. São Paulo: Summus, 2003. . COMUNICAÇÃO

ORGANIZACIONAL: Contextos, Paradigmas e Abrangência Conceitual.

Matrizes (Online), v. 8, n. 2, p. 35-61, 2014. Disponível em <http://www.revistas.usp.br/matrizes/article/v iewFile/90446/93218>. Acesso em: 04 nov. 2015.

LEITÃO, S. P. O poder no contexto da decisão organizacional. Revista de Administração Pública, v.30, n.2, p. 137151, 1996. Disponível em <http://bibliotecadigital.fgv.br/ojs/index.php/r ap/article/view/8328/7105>. Acesso em: 08 nov. 2014.

LIMA, S. M. L. Definição e implementação de objetivos nas organizações públicas de saúde. Revista de Administração Pública, v. 28, n. 4, p. 38-64, 1994. Disponível em $<$ http://bibliotecadigital.fgv.br/ojs/index.php/r ap/article/view/8328/7105>. Acesso em: 08 nov. 2014.

LOSEKANN, V. L; SALDANHA, J. M. A Universidade Federal Inserida num Contexto Globalizado de Reformas e Inovações do 
Estado Contemporâneo. Revista Sociais e Humanas, v.20, Edição Especial, p.83-102, 2007. Disponível em <http://cascavel.ufsm.br/revistas/ojs2.2.2/index.php/sociaisehumanas/article/view/ 830/568 >. Acesso em: 08 nov. 2014.

MENDES, P. J.V.; GUIMARÃES, T. A. Gestão da flexibilidade organizacional em ambiente de P\&D: alcance e limites da divisão do trabalho por processos. In:

ENCONTRO NACIONAL DOS PROGRAMAS DE PÓS-GRADUAÇÃO EM ADMINISTRAÇÃO, 26, 2002,

Salvador. Disponível em <http://www.anpad.org.br/diversos/trabalhos/ EnANPAD/enanpad_2002/COR/2002_COR3 28.pdf $>$. Acesso em: 10 abr. 2015. Acesso em: 04/11/2015.

\section{MINTZBERG, H. Criando organizações} eficazes: estruturas em cinco configurações. São Paulo: Atlas, 2006.

MINTZBERG, H.; AHLSTRAND, B.; LAMPEL, J. Safári de estratégia: um roteiro pela selva do planejamento. $2^{\mathrm{a}}$. Ed. Porto Alegre: Bookman, 2010.

MORENO, N. A. A Informação e o Processo de Tomada de Decisão. Informação \& Sociedade: Estudos, João Pessoa, v. 17, n. 1, p. 13-21, jan/abr. 2007. Disponível em <http://www.ies.ufpb.br/ojs2/index.php/ies/art icle/view/483/1461>. Acesso em: 13 nov. 2014.

MOTTA, P. R. O estado da arte da gestão pública. Revista de Administração de Empresas. vol.53, n.1, p. 82-90, 2013. Disponível em <http://www.scielo.br/pdf/rae/v53n1/v53n1a0 8.pdf>. Acesso em: 02 out. 2015.

OLIVEIRA, D. P. R. Sistemas, organização e métodos: uma abordagem gerencial, $17^{\circ}$ ed. São Paulo: Atlas, 2006.

PAES DE PAULA, A. P. Administração pública brasileira: entre o gerencialismo e a gestão social. Revista de Administração de Empresas, v. 45, n. 1, p. 36-49, 2005.

Disponível em <http://www.scielo.br/pdf/rae/v45n1/v45n1a0 5>. Acesso em: 13 nov. 2014.

PATINI, A. C. G.; FIGUEIRA, J. C.; FERNANDES, V. Mudança Na Estrutura Organizacional na Visão dos Trabalhadores em Nível Gerencial - Um Estudo de Caso em uma Empresa do Setor Químico. Revista Administração em Diálogo, v. 12, n. 3, p. 111-135, 2010. Disponível em <http://revistas.pucsp.br/index.php/rad/article/ view/4285/3242>. Acesso em: 10 abr. 2015.

PICCHIAI, D. ESTRATÉGIA, ESTRUTURA E COMPETÊNCIAS: Três Empresas de Serviços em Saúde. Cadernos Gestão Pública e Cidadania, 2010, v. 15, n. 56, p. 126-154. Disponível em $<$ http://bibliotecadigital.fgv.br/ojs/index.php/c gpc/article/view/3206/2100>. Acesso em: 10 Abr. 2015.

QUINN, J.; ANDERSON, P.; FINKELSTEIN, S. Novas formas de organização. In: MINTZBERG, H. QUINN, J. O processo de estratégia. $3^{\mathrm{a}}$. Ed. Porto Alegre: Bookman, p. 157-167, 2001.

SANTOS, J. L. S.; SOUZA, L. L. C. Gestão do Conhecimento em Organizações Públicas: transferência de conhecimento suportada por tecnologias da informação e comunicação. In: KM Brasil, SBGC, p. 1-11, 2008. Disponível em <http://www.ngs.ufsc.br/wpcontent/uploads/2010/06/2008_KM_TIC_KM -Brasil.pdf>. Acesso em: 17 nov. 2014.

SECCHI, L. Modelos organizacionais e reformas da administração pública. Revista de Administração Pública, v. 43, n. 2, p. 347-369, 2009. Disponível em <http://www.scielo.br/pdf/rap/v43n2/v43n2a0 4.pdf $>$. Acesso em: 17 nov. 2014.

SILVA, C. F. Alternativas para uma nova governança pública em ambiente democrático. In: III Seminário - 
Democracia, Direito e Gestão Pública. II Ciclo de Debates Direito e Gestão Pública, Brasília, Governo Federal, p. 70-76, 2011. Disponível em <http://www.gestaoemdestaque.gov.br/secreta rias/upload/Arquivos/noticias/seges/111118_e ncontro.pdf>. Acesso em: 17 nov. 2014.

TOFFLER, Alvin. Future shock. New York: Bantam, 1970.

TORQUATO, G. Tratado de comunicação organizacional e política. São Paulo:

Pioneira, 2002.

VASCONCELLOS, E. P. G. Estrutura das Organizações. 2. Ed. São Paulo: Pioneira, 1989.
VELOSO, E.; TREVISAN, L. ESTRATÉGIAS ORGANIZACIONAIS E PROCESSOS DE FUSÃO: Estudo de Caso Sobre Mudanças de Estrutura em Agências Bancárias. Revista Administração em Diálogo, v. 12, n. 3, p. 60-79, 2010.

Disponível em <http://revistas.pucsp.br/index.php/rad/article/ view/4707/3274>. Acesso em: 10 abr. 2015.

WEBER, M. Economia e sociedade (vol. 1). Tradução de Regis Barbosa e Karen Elsabe Barbosa, 2012. Brasília, Editora da Universidade de Brasília. 